\title{
Exploring Different Faces of Mass Customization in Manufacturing
}

\author{
Golboo Pourabdollahian, Marco Taisch, and Gamze Tepe \\ Politecnico di Milano, Piazza Leonardo Da Vinci 32, 20133, Milan, Italy \\ \{golboo.pourabdollahian, marco.taisch\}@polimi.it
}

\begin{abstract}
The present research aims at developing a framework to support MC companies in understanding different considerations and issues of mass customization manufacturing (MCM). It introduces crucial aspects of MCM by analyzing existing MC enablers and technologies as well as the trending ones which might be used in future of mass customization manufacturing. The framework is developed in two levels grounding on both literature and practical findings.
\end{abstract}

Keywords: Mass Customization, Manufacturing.

\section{Introduction}

Mass customization refers to producing personalized goods and services with an efficiency close to mass production $[4,3,6]$. A successful implementation of this strategy is based on the accurate design of the entire supply chain. The value chain must be a cooperation oriented network since mass customization primarily aims to satisfy individual needs of customers. Going through literature, "Mass Customization" and particularly MC manufacturing were discussed in numerous articles; but linkages between various manufacturing paradigms, enablers and factors influence MC manufacturing have been rarely covered. This paper aims to present both the current state and the future directions of mass customization manufacturing by integrating data from literature and case studies. Accordingly by analyzing MCM and its different aspects, a conceptual framework will be proposed presenting the main considerations while establishing an accurate MCM system. The framework pictures which factors contribute to the concept and also introduces the different aspects of a successful MCM implementation. The fundamental part of the framework constitutes the exploration of related enablers which address the manufacturing methodologies that are widely debated in the academia as well as enabling technologies which are suggested to be applied. Moreover, the framework includes a future look at the concept of MCM by presenting the cutting edge trends and technologies which are foreseen as potential to align with the manufacturing of mass customized goods. 


\section{Mass Customization in Manufacturing}

The implementation of mass customization requires integration of different manufacturing technologies into a structured framework capable of combining human and technological factors [1]. In recent years manufacturing systems have been evolving to satisfy the rapid change of customers' needs and preferences. In this regard several production paradigms, systems, methodologies and enablers for mass customization have been introduced in literature. In this paper we categorize Mass Customization Manufacturing (MCM) enablers in literature into two main categories which will be presented later in the proposed framework: 1) MC operational methodologies 2) MC enabling technologies.

MC operational methodologies refer not only to manufacturing and operational aspects of mass customization implementation but also to organizational and cultural aspects. This category includes methodologies such as lean manufacturing, cellular manufacturing and agile manufacturing. It should be mentioned that a methodology is composed of a set of practices which make it different from the term 'method'. In the context of production, the term 'method' simply corresponds to different aspects of specific techniques that are utilized in a manufacturing methodology. For instance, lean manufacturing, as a methodology, can choose to exploit different production methods whether job production or flow production depending on its needs or other factors. While methods have unidirectional approach which is production-oriented that makes it to focus on a tactical or operational level (maintaining efficiency, etc.), the methodology has a broader perspective that is based on a philosophy at most of the times (customer focus, collaborative mindset, supply chain, etc.).

The second category, MC enabling technologies, refers to subsystems and technologies which facilitate implementation of mass customization. These technologies can be either manufacturing and production technologies or information technologies. Customer-centric vision of mass customization makes it crucial for companies to have a flexible production system and a smooth information flow in company along the supply chain. In this regard, MC enabling technologies such as flexible manufacturing systems (FMS), Reconfigurable manufacturing systems (RMS) and Additive manufacturing technology act as facilitators while pursuing mass customization.

\section{Research Methodology and Data Collection}

The current study is based on two main types of research methodologies: literature review and empirical findings. Applying these two methodologies enriches the results of this study by combining proposals from academia and literature to real practices of mass customization manufacturing in different industries.

Empirical findings are collected via two types of information sources: primary sources and secondary sources. Regarding primary sources, three mass customization companies operating in three different sectors were analyzed. Required data for each case study were collected via interviews and surveys. Secondary sources for empirical findings include case studies presented in literature. Data were collected through 
different sources including papers, releases and publications on scientific magazines, official company website, official financial reports, blogs, forums, communities and online sector magazine release. Different practices regarding mass customization manufacturing in these case studies were studied to collect required data and integrate them with data collected from other sources in order to develop the MCM framework. Table 1 illustrates the general information regarding these case studies.

Table 1. Analyzed case studies

\begin{tabular}{|l|l|l|l|l|}
\hline Company & Country & Industry & Size & Type of data \\
\hline A & Italy & Diamond Wires & SME & Primary \\
\hline B & Switzerland & Kitchen & SME & Primary \\
\hline C & Italy & Footwear & SME & Primary \\
\hline D & Finland & Footwear & SME & Secondary \\
\hline E & UK & Material handling equipment & SME & Secondary \\
\hline
\end{tabular}

\section{$4 \quad$ Proposed Framework for Mass Customization Manufacturing}

Based on the collected data, a conceptual Mass Customization Manufacturing (MCM) framework was developed. The framework aims to visualize the state-of-the art of mass customization manufacturing, to provide a more clear and comprehensive focus on requirement for MC manufacturing, to create a comparison between various manufacturing paradigms and lastly, to explore future trends and direction of the concept.

The framework is developed in two layers. The first layer maps the position of mass customization manufacturing and related factors and requirements (figure 1).

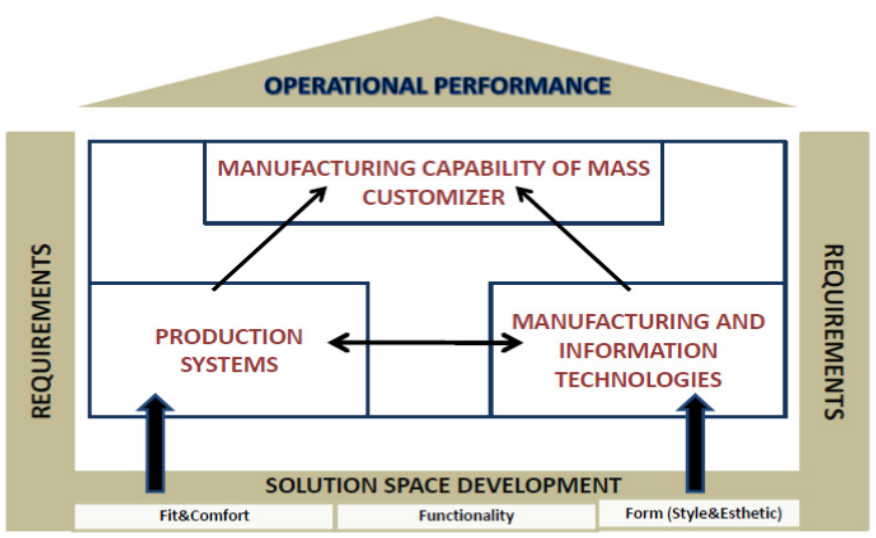

Fig. 1. General MCM framework (first layer of framework) 
The initial framework consists of several interdependent building blocks. Interaction of all these blocks leads to operational performance of a MC company. In following a brief description of each block is given.

- Solution space development is the beginning point of the framework. It is defined as one of the fundamental capabilities to support a company to implement mass customization successfully [5,7]. In a MC environment it is necessary to identify the idiosyncratic demands of customers and transfer this knowledge into an advantage to create a stable solution space enabling company to adjust the cost and the complexity of customer needs [2]. In this paper three axes of customization namely fit \& comfort; functionality and style have been defined for development of a solution space.

- Requirements refer to a set of factors demonstrating competitive opportunities and limitations of a MC company. While some of the factors would generate constraints during the implementation of mass customization, some others might enable the company to improve the manufacturing capability and consequently the competence of $\mathrm{MC}$ manufacturing. The factors are determined by considering the primary impacts on $\mathrm{MC}$ manufacturing related strategies.

- $\quad$ Production systems and manufacturing / information technologies are two crucial elements in mass customization manufacturing. A MC manufacturing system must be well designed by applying the appropriate production systems with exploiting suitable technologies to facilitate both flexible production and smooth information flow. Production systems can utilize different types of technologies due to their attributes. A MC manufacturer must be aware of which production system is more suited to its circumstances. Then, different technologies should be examined to find out whether they are applicable in a particular system or not. Production systems and manufacturing technologies determine the existing capability of a mass customizer.

- Operational performance addresses the potential outcome of the conceptual framework. When the production aspects of mass customization is considered, a mass customizer's primary goal should be to excel in its operational performance as high as possible. The operational performance of a MC company is a direct result of its capability to satisfy customers' individual needs while being efficient.

The generic nature of the first layer of framework necessitates development of the second layer with a more detailed focus on each block. The final framework is the outcome of integration of theoretical and practical findings from literature and case studies. It exhibits in detail the building blocks of general framework (figure 2).

As shown in figure 2, MC manufacturing capability is positioned in the core of the framework since it stems from three actors of MCM: manufacturing methodologies, enabling technologies, and future trends. Specifically, for each actor the potential enablers of mass customization manufacturing are identified and introduced in the model. Additionally, the requirements are redesigned and illustrated as four main 


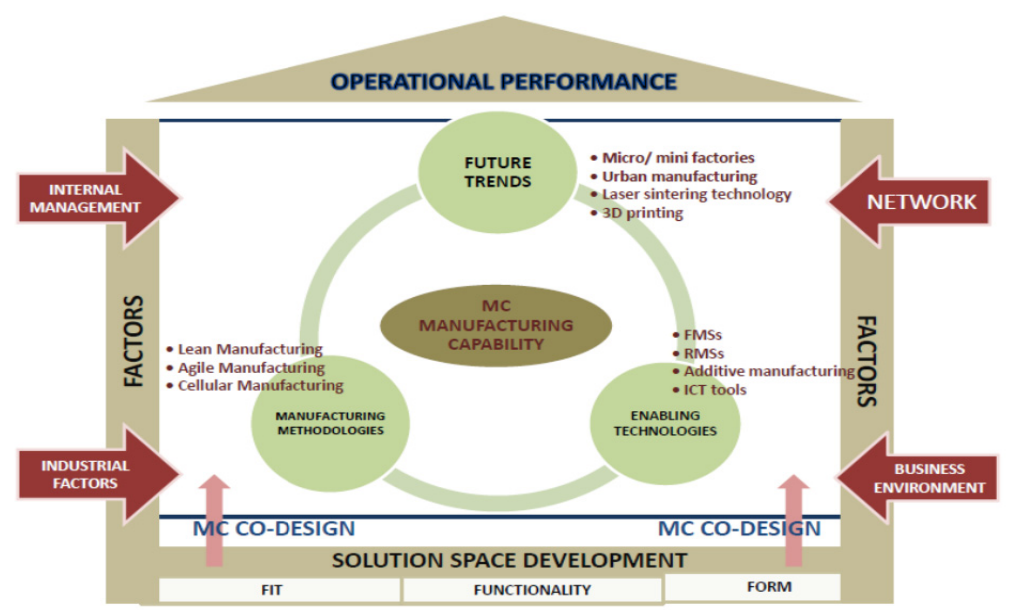

Fig. 2. Final MCM framework (second layer of framework)

factors. In following these four factors along with other building blocks of final framework have been briefly described.

- Internal management refers to management issues within an organization which have a significant impact on successful implementation of mass customization. In this paper we have mainly split theses factors into two categories: first, Investment and cost considerations that is a crucial element for mass customization manufacturing. Empirical findings from analyzed case studies highlight the point that MC companies usually face the dilemma of deciding to what extent the automation should be adopted to improve custom manufacturing since most of the technologies require considerable initial costs and efforts. Second category relates to organizational readiness. A company pursuing MC strategy must pay attention to prepare the entire organization for changes towards mass customization considering the fact that usually there is a resistance against change inside of an organization.

- Industrial factors play a crucial role in mass customization manufacturing. The state of the art of manufacturing may vary from one industry to the other. While some industries such as electronics and automotive are ground on high-tech solutions for production some other sectors are not pioneers to lead manufacturing. The case of Levi's is a well-known example due to its failure to maintain Mass Customization strategy. The company was one of the first customizers at the very beginning of $\mathrm{MC}$ implementations. However, it couldn't well establish a proper production system that enables efficient custom jeans manufacturing. One remarkable reason behind the failure was the current technology state of clothing industry that caused Levi's finally to abandon its pursuit of MC. Today rapid advances in computer and manufacturing technologies encourage companies to transform their conventional manufacturing into emerging patterns to answer changing demands. 
- Networks are necessary to make integration among different actors in a $\mathrm{MC}$ environment. Since custom production requires efficiency and timeliness, a MC manufacturer has to build a smooth communication between its suppliers as well as customers. Trustworthy supply networks ease the manufacturing of individual customer orders which necessitate an excellent production and process planning.

- Business environment in this study is grouped into three main categories. 'Competitive environment' in the market, 'customer customization sensitivity' regarding which enables company to determine its offered level of customization and efficiency and finally 'regulations' which vary among different industries / countries and act as limiting factors.

- Manufacturing methodologies, as described in section 2, refer to a set of technological, managerial and human force issues of a production paradigm. Table 2 illustrates a comparison among three different manufacturing methodologies proposed for mass customization in this paper.

- Enabling technologies refer to manufacturing or information technologies acting as facilitators to pursue mass customization manufacturing. Some notable examples in this regard are: Computer Aided Design (CAD), Computer Aided Manufacturing (CAM), automated handling system (including different types of AGV and conveyors), generic modular mechtronic control, reconfigurable machining system and robotic devices, etc.

- $\quad$ Future trends is an important block of MCM framework which can bring competitive advantage to a MC company by implementing innovative and trending technologies in the field of mass customization technologies. Inn this paper trending manufacturing technologies which can support mass customization in terms of manufacturing are divided into three main categories. First category is "micro-factory" which is a new type of small manufacturing system that utilizes less space and reduced consumption of resources as well as energy via downsizing of production processes to have higher throughput. Micro-factories should comprise of extremely precise machining, gripping, and handling units with user friendly interfaces in order to be efficient. Enterprises that are in pursuit of MC manufacturing can gain some substantial advantages from the adoption of micro-factories in terms of shorter process chain, space reduction, quicker response, flexibility, modularity in processes, and cost reduction. Second category relates to "laser sintering technology" which has gained a great attention as an advanced manufacturing process to fabricate products based on electronic data and stimulate new aspects for customization in terms of rapid change and flexibility. Today, laser-dependent technologies shift from being an R\&D tool to a promising manufacturing method realizing fabrication of customized products. Finally the third category refers to "3-D printing" which is a manufacturing technique used in Additive manufacturing technology. 3D printing can be used in plenty of fields and it is expected to expand its application in field of mass customization thanks to increasing demand of personalized products. 
Table 2. Summarized comparison of different manufacturing methodologies for MC

\begin{tabular}{|c|c|c|c|}
\hline & Lean Manufacturing & Agile Manufacturing & $\begin{array}{c}\text { Cellular Manufacturing/Group } \\
\text { Technology }\end{array}$ \\
\hline Characteristics & $\begin{array}{l}\text { - ability to respond to competitive } \\
\text { pressures with limited resources } \\
\text { - a collection of operational techniques } \\
\text { focused on productive use of resources } \\
\text {-suitable for high and stable demand } \\
\text { level } \\
\text { - high and stable demand level }\end{array}$ & $\begin{array}{l}\text { - a strategic vision which is capable to adapt } \\
\text { continuous and unpredictable change } \\
\text {-cooperativeness and synergism -most likely- } \\
\text { created with virtual corporations } \\
\text {-necessity for sharing resources\&technologies } \\
\text { among companies } \\
\text { • an information infrastructure linking } \\
\text { constituent partners in a unified electronic } \\
\text { network } \\
\text {-integration of advanced internet and } \\
\text { manufacturing technologies with conventional } \\
\text { design\& manufacturing techniques }\end{array}$ & $\begin{array}{l}\text { - a philosophical tool to arrange the product } \\
\text { parts into group (product families) with regards } \\
\text { to their similarities in terms of } \\
\text { design\&production process. (GT) } \\
\text { - an application of Group Technology in which } \\
\text { machines are } \\
\text { - traditional cellular layout is appropriate in } \\
\text { medium-variety, medium-volume environments }\end{array}$ \\
\hline Advantages & $\begin{array}{l}\text { - elimination of waste } \\
\text { - lowering manufacturing cost due to its } \\
\text { waste eliminating } \\
\text {-quality oriented approach } \\
\text {-widespread in many sectors including } \\
\text { automotive, electronics, white goods, } \\
\text { consumer products manufacturing etc. } \\
\text {-focus on preventing breakdowns } \\
\text { rather than fixing them }\end{array}$ & $\begin{array}{l}\text {-suitable for unpredictable \& dynamic demand } \\
\text { with a high degree of mass customization in its } \\
\text { products } \\
\text {-proactive adaptation while FMS is concerned } \\
\text { more as a reactive adaptation } \\
\text { - reduction in set-up time and costs }\end{array}$ & $\begin{array}{l}\text { - standardization of tooling, fixturing, and set- } \\
\text { ups } \\
\text { - reduced set-up times and shorter } \\
\text { manufacturing lead times } \\
\text { - reduced in-process inventory } \\
\text { - shorter travelling distances and time } \\
\text { - easier material handling activities } \\
\text { - simplified process planning and production } \\
\text { scheduling }\end{array}$ \\
\hline Challenges & $\begin{array}{l}\text { - Iong term commitment to the concept } \\
\text { with no short term outcomes } \\
\text { •significant transformation is required } \\
\text { in the entire company to have a 'Lean } \\
\text { Thinking' } \\
\text {-dependency on suppliers' efficiency }\end{array}$ & $\begin{array}{l}\text {-skilled labor required to operate different } \\
\text { systems } \\
\text { • application costs of new technologies } \\
\text {-difficulties to distribute the workload among } \\
\text { partners } \\
\text { •high requirement of an integrated production } \\
\text { planning, scheduling and control system } \\
\text {-need of instant re-scheduling or re-selection } \\
\text { of partners }\end{array}$ & $\begin{array}{l}\text { - difficulty of part family grouping and cell } \\
\text { design (time-consuming) } \\
\text { - in case of a machine breakdown work } \\
\text { stoppage within the cell } \\
\text {-increased capital investment } \\
\text {-labor resistance (facilitates cross training) }\end{array}$ \\
\hline Linkages to MC & $\begin{array}{l}\text {-Torsten et al. (2007): an empirical study } \\
\text { conducted in the furniture industry. } 21 \\
\text { out of the } 23 \text { respondents mentioned } \\
\text { the necessity of the implementation of } \\
\text { lean manufacturing concepts to support } \\
\text { MC. }\end{array}$ & $\begin{array}{l}\text { - Cho et al.(1996): agile manufacturing } \\
\text { description as "the capability to survive and } \\
\text { prosper in a competitive environment of } \\
\text { continuous and unexpected change by reacting } \\
\text { quickly and effectively to changing markets, } \\
\text { driven by customer-designed products and } \\
\text { services". } \\
\text {-Yang and Li (2002): MC product manufacturing } \\
\text { agility evaluation index system is established } \\
\text { with an example of Xi Dian Casting Limited } \\
\text { Company. Agility assessment of an MC } \\
\text { manufacture system is formed by three aspects: } \\
\text { enterprise organization management, products } \\
\text { design and processing and manufacturing. }\end{array}$ & $\begin{array}{l}\text {-Badurdeen (2005): minicell configuration } \\
\text { which divides traditional cells into small } \\
\text { multi-stage cells to realize the mass } \\
\text { customization manufacturing. } \\
\text {-Akturk and Yayla (2005): a hybrid model which } \\
\text { integrates the cellular manufacturing system } \\
\text { design and appropriate technology selection } \\
\text { for dynamic market fluctations, or custom } \\
\text { products. } \\
\text { - Suzic et al. (2012): an empirical study applies } \\
\text { Group Technology layout into a furniture } \\
\text { manufacturer. Particularly, it attempts to } \\
\text { transform the business from mass production } \\
\text { to mass customization. }\end{array}$ \\
\hline
\end{tabular}

\section{Conclusion}

Mass customization is a strategy which has gained the growing attention of different industries in recent years. One of the critical issues for companies pursuing mass customization is to design their MC manufacturing system. A proper MCM system should focus on flexibility and quick responsiveness to individual customer orders which is based on the balance between pure customization and mass production. The success of customized products manufacturing is dependent on the product and process development which also addresses the importance of balancing basic choice offerings and wide variety of offerings. The proposed MCM framework in this paper is developed based on theoretical and empirical data in order to support companies to follow a successful pursuit of mass customization manufacturing. Collected data from case studies highlight the fact that although the literature links MCM to some 
production methodologies, described in this paper, but it is less likely to encounter the real practices of these methodologies in enterprises. This is a gap which can be filled by a more efficient knowledge transfer between academia and industry. The presented framework is a general-purpose version without focusing on any specific industry. This was mainly due to the limited samples caused by both the lack of real company cases and the absence of extensive case practices covering manufacturing sides of MC in the literature. However a future work to make a tailored framework for a specific sector would increase the added value of the work and the feasibility of validation phase as well.

\section{References}

1. Da Silveira, G., Borenstein, D., Fogliatto, F.S.: Mass customization: Literature review and research directions. International Journal of Production Economics 72(1), 1-13 (2001)

2. Piller, F.T., Tseng, M.M.: Mass Customization Thinking: Moving from Pilot Stage to an Established Business Strategy. In: Handbook of Research in Mass Customization and Personalization, Aachen, Germany (2010)

3. Piller, F.T.: Mass customization: reflection on the state of the concept. International Journal of Flexible Manufacturing System 16(4), 313-334 (2004)

4. Pine, B.J.: Mass Customization - The New Frontier in Business Competition. Harvard Business School Press, Boston (1993)

5. Salvador, F., De Holan, P.M., Piller, F.T.: Cracking the code of mass customi-zation. MIT Sloan Management Review 50(3), 70-79 (2009)

6. Tseng, M.M., Jiao, J.: Mass Customization. In: Handbook of Industrial Engineering, Technology and Operation Management, 3rd edn., Wiley, New York (2001)

7. Von Hippel, E.: User Toolkits for Innovation. Journal of Product Innovation Management (18), 1-28 (2001) 